\title{
An Overview of History of Contract Law Translation in China
}

\author{
Lin Sun \\ School of Foreign Languages, Southwest University of Political Science and Law, China \\ Dexiang Gong \\ Southwest University of Political Science and Law, China
}

\begin{abstract}
Legal translation enjoys significance in both empirical and theoretical aspects, while the historical perspective can help the academia and translators to know the past of certain specific field of laws so as to produce better translation versions. Based on commonly accepted translations theories, this article explores the historical importance of contract law in perspective, analyzes the process of development, exhibits the translation achievements and experiences from major translators and agencies, thus, some paradigm and future advices can be drawn therefrom. Employing a theoretical method in a history angle is not that frequently used in translation practice, however it is also not that rare, it can be a start for not only contract law per se, but the whole legal translation in balance.
\end{abstract}

Index Terms - historical theory, contract law, translation, paradigm

\section{INTRODUCTION}

In the study of legal translation, historical perspective draws little attention by the academia, yet it is essential to help the translators to practice better after knowing the histories of one specific aspect, the major translators and translation agencies, from whom the theoretical analysis can hopefully provide useful reference in future legal translation. Application of translation theoretical history can be focused on certain law in a narrow sense to demonstrate the method of study. This article, for example, will take an angle of contract law. As a matter of fact, the translation of laws began in China since Qing Dynasty, as of today, the law translating become common and necessary. Contract law, as an important market transaction rule, not only serves the domestic market, but also has great significance in the international market in the era of globalization. Therefore, China's contract law has been translated into many languages, as for English versions, there are several different ones. A standardized translation of contract law can avoid transaction risks caused by language ambiguity and ensure transaction safety, and help to improve the openness of China's laws and promote the exchange and dissemination of China's rule of law concept and legal culture (Li Jie, 2013).

To be mentioned, legal translation is more specialized and technical than general translation, and of course more difficult, hence legal document is regarded as one of the most difficult types of texts to translate. Since legal language itself has the characteristics of accuracy and seriousness, and different legal systems have different legal cultures, translators should observe certain methods and principles in the translation process in order to achieve parity in the legal languages of different countries as far as possible. Since legal translation is considered a special type of translation, it is necessary to understand the prevailing translation theories in China and abroad. In the development of China's contract law, a large number of translations of legal texts and jurisprudential works from Western countries are taken as references, among which the works in English will be taken into account in this article. It's notable that there are great differences in legal culture and systems between China and common law countries, due to the institutional differences between them, there will always be abundant hard issues to crack, such as linguistic heterogeneity, which may arise due to the different cultures of common law systems and the ambiguity of language; the lack of uniform standards in the early stages of translation, which leads to confusion in the translation names.

The translation of contract law also has been guided under translation principles and theories, some of those are well-recognized since its beginning. In China, the most famous theory comes from through Yan Fu, a famous translator in Chinese history, who put forward the famous "faithfulness, expressiveness and elegance" doctrine during the translation of the Treatise on the Evolution of Heaven, which had a profound influence on modern Chinese translation (Guo Fang, 2016). The so-called "faithfulness, expressiveness and elegance", in plain words, means that the translator should be faithful to the original text, accurate and fluent in expressing the meaning, beautiful in writing and rich in literary style when translating. Yan Fu's translation theory has influenced Chinese translation scholars since the late Qing Dynasty until now, and is one of the most influential translation theories in China. Meanwhile, in the west, the most famous "dynamic equivalence" translation theory was advocated in 1964 by Eugene Nida (1964), "the patriarch of translation study and a founder of the discipline", who exerted a great influence all over the world (Snell-Hornby, 1988; Baker, 2006). This theory focuses on achieving functional equivalence of language, which means, the translation should be able to make the readers of the translation feel similar to the readers of the original text when they read it. Nida's 
theory has been attracting much attention since it was introduced to China in the 1980s. Guided by these translation theoretical doctrines, China's contract law translation developed so rapidly in the last four decades, that other laws can hardly surpass it.

\section{Developing Process of CONTRACt LAW IN China}

It did not start as a "contract law" in China as a matter of fact. The enactment of the Economic Contract Law of the People's Republic of China on July 1, 1982 announced the official beginning of the history of contract law in China. Later, in order to protect the legitimate rights and interests of the parties to foreign-related economic contracts and promote the development of China's foreign economic and trade relations, on March 21, 1985, China promulgated the Law of the People's Republic of China on Foreign-Related Economic Contracts. To promote the development of science and technology as well as protect the legitimate rights and interests of the parties to the contract, on June 23, 1987 , China promulgated the Law of the People's Republic of China on Technology Contracts. Not before long, the General Principles of Civil Law of the People's Republic of China was also promulgated on April 12, 1986, and came into effect on January 1, 1987. Before the promulgation of the Contract Law of the People's Republic of China, the field of contract law in China presented a confusing situation of three laws co-existing, namely the Economic Contract Law of the People's Republic of China, the Law of the People's Republic of China on Foreign-related Economic Contracts and the Law of the People's Republic of China on Technical Contracts, and there were many legislative contradictions among the three, so the introduction of a unified contract law was particularly important. It was against this background that the Contract Law of the People's Republic of China was finally adopted by the National People's Congress on March 15, 1999, after four years of revision, and came into force on October 1, 1999.

Since then, in order to further promote the comprehensive rule of law, China began to compile the Civil Code in 2015, and after years of brewing and drafting, through the persistent coordination of the legislature, the final result of gathering the academic achievements of generations of jurists and the practical experience of the rule of law in the practical community, the compilation was completed and published in 2020 that will come into force since January 1 , 2021. As a result of our national commercial codification style, contract law was incorporated into the Civil Code, thus, China's contract law has entered another climax. The table below can demonstrate the process in regard of contract law in China, which obviously illustrates that the contract law has become generalized during the past decades.

\begin{tabular}{|l|l|}
\hline Time & Name \\
\hline 1982 & the Economic Contract Law of the People's Republic of China \\
\hline 1985 & the Law of the People's Republic of China on Foreign-Related Economic Contracts \\
\hline 1987 & the Law of the People's Republic of China on Technology Contracts \\
\hline 1987 & the General Principles of Civil Law of the People's Republic of China \\
\hline 1999 & the Contract Law of the People's Republic of China \\
\hline 2021 & Civil Code of the People's Republic of China \\
\hline
\end{tabular}

No matter how the exact names have changed in contract law aspect, the legal terminology is always an important part in its expression, so the correct translation of legal terminology is the premise and foundation for translating the entire legal text. Thus, semantic equivalence should be maintained as much as possible in the translation process of the terms. However, there are many synonyms and near-synonyms in legal English terms, especially in contract aspect, encountering words expressing similar or same meanings in different contexts is hence inevitable (Daria Martemianova, 2019). Different scholars hold different views on the strategies and methods of translating contract law terms. Take Li Zhenyu and $\mathrm{Qu}$ Wensheng as an example, Li believes that from a macro perspective, the main methods of legal translation are direct translation, meaningful translation and direct meaning supplemental method (Qu Lin,2015). In addition, there are also many special translation methods for legal translation, such as direct translation with commentary method. Qu Wensheng's research on legal translation techniques mainly focuses on subtraction, addition and selection of word meanings. Contract law is the characteristic of common law, and the pluralistic and open style of British and American contract law is in line with the worldwide trend of unification and commercialization of contract law, which makes British and American contract law not only become the common rules of international business, but also profoundly influence Chinese contract law in a subtle way (Liu Chengwei, 2020).

Since the sentence structure of English and Chinese is different, English sentences pay more attention to logic and important information is often at the beginning of the sentence, which is very different from the grammatical structure of Chinese, the difficulty of translating sentences arises, and the translator needs to switch freely between English and Chinese. After completing the translation of terms and sentences, the importance of discourse becomes particularly acute. The translation of discourse is very important in legal translation because many terms and syntactic features can be perfectly explained only through their functions in discourse, the purpose of discourse analysis is to describe linguistic features that extend beyond the scope of the sentence. Identifying and analyzing legal discourse features is much more difficult than identifying and analyzing lexical and syntactic features; after all, the first two difficulties can be solved at the lexical and grammatical levels. However, the translation of the discourse requires the translator to choose the form of language expression that conforms to the expression habits of the target language, so that the translation can be fully understood by the readers. In the past, legal discourse analysis mostly focused on the fragment 
of text, but paid less attention to the similarities and differences between different texts and different language domains, which resulted in such defects as confusion and illogicality of discourse, and led to difficulties in translating discourse.

\section{EFFORTS OF MAJOR TRANSLATORS AND TRANSLATION AgENCIES}

The mature legal system of any country is inseparable from the contribution of legal translation, and the development of Chinese law to the Qing Dynasty, especially the more complete legal system in the late Qing Dynasty is more thanks to a large number of translations of legal texts and jurisprudential works of Western countries.

As the process of China's reform and opening up continues, foreign rule of law exchanges are becoming an important way for us to dialogue with the international community on an equal footing and safeguard our rights and interests. The translation of laws, regulations and rules is an important window to show the achievements of China's reform and opening up and rule of law construction. Over the years, the translation of laws, regulations and rules has fully demonstrated the good image of China's rule of law state and rule of law government, enhanced the country's soft power, and improved the international community's understanding and knowledge of China's economy, politics, culture and other aspects. The translation of laws and regulations is an important position for foreign exchange and plays an important role in China's foreign exchange. The English translations of laws and administrative regulations published in China are of great significance to other countries in systematically understanding our legal system. The importance of translation of laws and regulations in China is gradually increasing, and translation agencies and translation talents play an irreplaceable role in this process.

\section{A. Main Translators}

Translators are the key factor in legal translation, and the improvement and development of legal translation is often driven forward by the joint efforts of the translator community. The unification and standardization of the translation of legal terms is inseparable from the joint efforts of translators. Taking the term "Consideration" as an example, consideration is a core principle in British and American contract law, which is one of the necessary conditions for contract formation. To apply a historical analysis method, in all times of China, one meaning that expressed in the English term never appeared in China's legal system. Since there is no exact term corresponding to it, translators then are supposed to notice even the slightest differences to make some degree of creation under reasonable circumstances to seek the deeper meaning of this legal concept to correspond to China's law. Right now, there are two major Chinese translations of this term in China: “对价” and “约因” (Yu Danling, 2009). When encountered in different occasions, the translator will decide which Chinese version should be, during which, the historical perspective can just do the assistance for accuracy.

TABLE 2

\begin{tabular}{|l|l|}
\hline English concept & Chinese translation choice \\
\hline \multirow{3}{*}{ consideration } & $\begin{array}{l}\text { “对价”Dui Jia means one party gives another party some rights/interests/profits/endurance, } \\
\text { etc. This meaning is included in Chinese legal history, and existing laws. }\end{array}$ \\
\cline { 2 - 3 } & $\begin{array}{l}\text { “约因”Yue Yin means a promise for which one party has to pay something to make it legally } \\
\text { bounding. Since this meaning is not included in China's legal provisions historically, when } \\
\text { conducting EC translation, it's essential to think about its context and apply explanation } \\
\text { when necessary. }\end{array}$ \\
\hline
\end{tabular}

The word "consideration" above is just one leaf in the forest, while the reality in translation has always been even more complicated. However, a lot of translators have devoted in legal translation process, and made quite achievements. The earliest translators of Western political and legal thought to the Chinese were missionaries from the West, such as Morrison, Millais, and Guo Shira. They used their limited knowledge of Chinese to translate and import various political and legal ideas of the modern West to the Chinese people. A series of legal terms with rich connotations, such as "equality before the law," "separation of powers," and "judicial independence", were translated into China at this time. In addition, the pioneers of modern legal translation were not the Chinese themselves, but the clergy from the West, among whom the earliest translators of foreign legal documents to China were American William Ding and English Lanya Fu. They were the foreign translators who translated the largest number of legal and juridical works for China and had the most far-reaching impact.

Modern influential Chinese legal translators are also numerous, like Chen Zhongcheng, Li Kexing, Li Changshuan and so on. Chen Zhongcheng was the compiler of the Yuanzhao Dictionary of English and American Law. Mr. Chen's translation works are more practical in content, and he also gives his own translation principles for vocabulary translation, namely, the principle of "phonetic priority" and the principle of "unification" (Yu Lu, 2015). Li Kexing (2020) arguess that the greatest difficulty in English to Chinese translation of legal texts is the understanding of long sentences, and that to understand long sentences exactly is often the greatest problem faced by translators. In response to this assertion, through a series of researches, he gives the basic rules and processes of English to Chinese translation of complex legal texts. He believes that in translating complex legal texts, in order to translate a legal text with professional standard and can be put into practice, the translator needs to be familiar with relevant legal knowledge, and the first thing he should understand is the sentence structure of the original text, the grammatical relationship of each component of the sentence, etc. In his book Legal Translation and Legal Texts, he proposed the method of translating 
long and difficult sentences by "turning vines into bamboo sections", and also put forward his own opinions and views on other aspects of legal translation, making great contributions to the translation of long legal sentences. He believes that conditional sentences with "where" as the guiding word are most suitable for expressing legal provisions that do not depend on the context, while conditional sentences with "if" as the guiding word are often used to express conditions or restrictions of lower importance and dependence (Li Kexing, 2018). After a comparative study of existing translation strategies, he proposed the concept of "static equivalence" as opposed to "dynamic equivalence", taking into account the special and specialized nature of legal translation (Li Kexing, 2010).

Li Changshuan (2019) argues that terminology translation, like scientific research, requires a scientific method to guide the process of finding a perfectly equivalent or almost perfectly equivalent translation through repeated investigation and verification. He thinks that translation can be divided into three aspects: understanding, expression, and trade-off (Li Changshuan, 2017), and how to perfectly accomplish the above three aspects requires cultivating sufficient critical thinking. In response to the problem of inaccuracy and unnaturalness of the concept of translation, he proposes the method of qualitative and quantitative analysis to ensure the accuracy and naturalness of the translation. He also proposes a reasonable solution on how translators should deal with errors in the original text found during the translation process - correcting or pointing out errors in the original text. In addition, he introduces the concept of "parallel text" in his book Non-literary Translation, which refers to the original text and the translation that can be read side by side, sentence by sentence (Li Changshuan, 2006). In the process of translation, by reading a large number of parallel texts, translators can find more vivid and authentic expressions, and at the same time, they can complete the translation more quickly and improve efficiency.

\section{B. Translation Agencies}

After Western law books are translated into Chinese, they must be presented to the Chinese people through certain media, and publishing books is a common way. Modern translation and publishing institutions are divided into official and unofficial. The official publishing institutions have a great advantage in terms of personnel, capital and equipment. The largest of the official translation institutions in the late Qing Dynasty were the Beijing Tongwenkan and the Jiangnan Manufacturing Bureau Translation Hall (Hu Zhaoqing, 2007). As the official translation institutions, they made great contributions to the translation of Western studies, among which the Beijing Shi Tongwenkan translated more than 200 kinds of Western books, and the translation hall of Jiangnan Manufacturing Bureau translated 199 kinds of Western books in 40 years, which included Western legal documents. Through the translation and publication of Western legal books, many modern Western legal ideas and systems were disseminated to the country, which to some extent contributed to the development and modernization of Chinese law. Unofficial publishing institutions include church publishing institutions as well as private publishing institutions. Representative ecclesiastical publishing institutions include Mohai Book House, Meihua Book House, and Puzzle Book Club. In the process of translating Western books in the late Qing Dynasty, church publishing institutions actively participated in the translation and publication of a large number of Western legal and political books, which made significant contributions to the introduction of Western studies. The representatives of private publishing institutions were the Commercial Press and Guangzhi Shuhui, among which the contribution of the Commercial Press in particular was the most outstanding. The main characteristic of private publishing institutions, which emerged in large numbers after 1898, was their relative economic independence and therefore considerable freedom in publishing content. It was because of these publishing institutions that Western law was able to spread in China and thus influence the development and reform of Chinese law.

Since the founding of New China, especially after the reform and opening up, China has gradually paid more attention to the translation of laws and regulations, and has set up several different institutions to specialize in legal translation work.

The Compilation and Translation Bureau of the Central Committee of the Communist Party of China (CPC), established in 1942, is an institution directly under the CPC Central Committee, whose main task is to compile and study the classic works of Marxism and translate the important documents of the Party and the state as well as the writings of leaders. The Bureau of Compilation and Translation of the CPC Central Committee has a large number of talents in translation, research, information and editing, and employs foreign experts in English, German, French and other languages to assist in its work all year round. It cooperates extensively with many related organizations and institutions at home and abroad, and the field of academic exchange is constantly expanding. The Central Compilation and Translation Bureau has organized the translation of a large number of English laws and regulations, which has greatly contributed to the progress of China's legal translation business.

The Legal Affairs Commission of the National People's Congress (NPC) was established in 1979, and the Commission is the legal working body of the NPC Standing Committee. It is responsible for compiling, translating and reviewing legal documents, etc. It is one of the most authoritative legal translation agencies in China. It plays a crucial role in the field of legal translation in China, and it has established working bodies dedicated to the validation of legal translation. The work of standardization and standardization of legal terms in China consists of two parts of work, namely, the unification and standardization of Chinese translation of foreign terms and the unification and standardization of Chinese legal terms for foreign translation. The current achievements of these two pieces of work are associated with the efforts of the Legal Affairs Commission of the NPC. The Committee is responsible for organizing 
and carrying out the validation of English translations of legal terms and promoting the popularization of unified translations of legal terms (Qu Wensheng, 2012).

In addition, the Ministry of Commerce and the Ministry of Foreign Affairs, as important subjects of China's foreign exchange, have also made great contributions in legal translation. The Ministry of Commerce has played a vital role in China's foreign trade activities since the reform and opening up, especially after China's accession to the WTO. The Foreign Affairs Department of the Ministry of Commerce has a Translation Division, which is specifically responsible for translating legal documents for foreign commerce and trade, etc. The Translation Division of the Ministry of Foreign Affairs of the People's Republic of China, one of the organizational bodies of the Ministry, is responsible for the translation of important national foreign affairs activities, diplomatic documents and papers, and undertakes the coordination of simultaneous interpretation and multilingual translation for major international conferences.

As for online legal translation websites, with the advent of the Internet era, the Internet has begun to penetrate into all aspects of society, and legal English translation has likewise begun to emerge in the Internet field. In order to improve efficiency, many legal people are able to make full use of all kinds of internet as well as big data. A number of legal English translation websites have been established to provide new channels for legal English translation in China. The emergence of these translation websites has not only improved the efficiency of people's daily legal search, but also promoted the development and progress of legal translation to a great extent. In this paper, it will take two relatively authoritative websites as examples to discuss such new legal translation media. The first one is PKU LAW.com, which is the first set of legal search software in China. It is a search platform jointly launched by Peking University Legal Information Center and Beida Ying Hua Technology Co. It is one of the longest-running comprehensive legal databases in China. Its content sections are of great variety, including the English section, which is a new way to present legal translation in the Internet era. The other one is WK Advance, which is a professional legal information search tool specially created by Dutch WK Group for the Chinese market. As a bilingual legal database, its English legal translation version is of high quality and has a strong reference role for legal translation. As a new type of legal search tool in the Internet era, it is a new way of legal translation.

\section{IMPACT AND REFLECTIONS FROM CONTRACT LAW'S TRANSLATION}

Since Chinese contract law was drafted relatively late, it was inevitably influenced by many foreign contract laws and international contract law documents. Moreover, contract law is a market transaction rule, and the Chinese must not only focus on the domestic market, but also look at the global market in the era of globalization, and therefore, in order to be in line with the international community, they must also absorb the legal system of advanced countries and international legal documents in contract law.

\section{A. Impact of Contract Law's Translation}

In addition to the contract law of specific countries, the development of China's contract law has likewise been influenced by many international documents like the General Principles of International Commercial Contracts and the United Nations Convention on Contracts for the International Sale of Goods.

The 1980 United Nations Convention on Contracts for the International Sale of Goods is the international legal document with the widest scope of influence, and as one of the earliest contracting parties to the Convention, China's contract law has drawn heavily on the relevant provisions of the Convention (Wang Liming, 2013). Specifically in the following aspects: (1) the formation of the contract, the Convention adopted the civil law country's doctrine of arrival, this rule is also adopted by China's contract law; (2) Performance of the contract, the Convention excludes the problem of failure to perform, This rule is expressed in our contract law that the parties do not have the right to dispose of the contract at the time of its conclusion, and the contract concluded by them is also valid; (3) Default system, the Convention establishes the rules of fundamental breach and anticipatory breach as well as strict liability for breach of contract, all of which have a profound impact on the development of China's contract law.

The Convention has had a positive impact on the formulation of relevant laws in China, promoting the convergence of China's law with international rules, and helping to eliminate legal obstacles in China's international trade, and promoting the healthy development of China's international trade. And all these beneficial results are inseparable from the contribution of legal translation. It is because of the existence of legal translation, a bridge between China and foreign laws, that China's contract law can be successfully connected with international legal documents and thus developed and improved.

The General Principles of International Commercial Contracts was published by UNIDROIT in 1994, and was a great success as a restatement of contract law at the international level, intended to be a "modern common law" reflecting the situation of all major legal systems in the world. It has influenced the drafting of Chinese contract law. The Chinese translation of the text was published in 1996 and has since entered the Chinese world and influenced the drafting of Chinese contract law (Han Shiyuan, 2015). The drafting of China's contract law has been profoundly influenced by a number of legal systems like "The subject matter of the contract cannot be performed from the outset", "Liability for contractual negligence" and "Pre-performance Defense".

Since the establishment of China's contract law, the amount of China's foreign trade has continued to increase, and the economic development trend is very good, especially after the reform and opening up, China has been upholding the 
policy of opening up to the outside world, the most important of which is reflected in foreign trade, which plays an irreplaceable role in the development of China's economy. From the following chart, we can see that since 1980, the total amount of import and export of goods in China has continued to rise, and this situation is inseparably linked to the continuous improvement of contract law.

图 12978 - 2010 年中国货物进出口情况

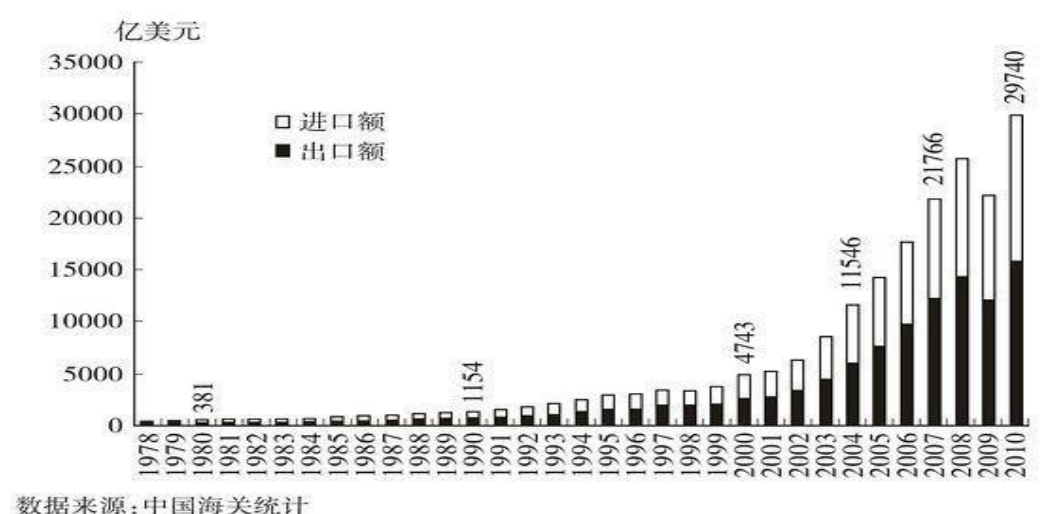

\section{B. Reflections from Contract Law's Translation}

Some insights and reflections can be drawn from the translation of contract law, and these insights and reflections play an important role not only for contract law itself, but also for the translation of other department laws.

From the above statements, it can be concluded that legal translation is a very complicated task. How to translate legal terms accurately is the most important part of legal translation work. The author believes that the best way to improve legal translation at present is to establish a parallel corpus. With the frequent international business transactions and the rapid development of machine translation, the traditional translation industry has encountered unprecedented challenges. In order to promote the improvement of legal translation efficiency, many translation service agencies have applied the machine translation mode to legal translation in practice. Machine translation mode has greatly saved translation cost and improved translation efficiency. However, this mode of translation requires a strong legal parallel corpus as support to ensure the accuracy of translation. Parallel corpus is a computer that incorporates the texts of two languages exactly corresponding to each other, and searches the source text against the translated text to find out the correspondence between them, so as to explore how the same content is expressed in two languages. The parallel corpus is a new resource that provides translators with a working platform and reference tools that can be used to improve linguistic and cultural knowledge (Jiang Ting, 2005). The parallel texts in the corpus are essentially interchangeable, and they are supposed to transform and absorb each other. Parallel texts are original texts and translations that can be placed side by side and read sentence by sentence against each other. Take the translation difficulties mentioned in the first chapter as an example, the contract formation system in China's contract law corresponds to the contract formation system in the common law, so when the parallel corpus is established, this corresponding system is the parallel text, and when the contract formation is searched in the corpus, the corresponding text can appear. Another example is the translation of terminology. By terminology translation, we mean the transition from one language form to another through parallel adaptation, in which the semantic core of the term does not change. Therefore, it is possible to build a corpus of target language terms that are equivalent to the source language terms. In practice, due to the differences in legal system, legal system, legal culture, etc., it is easy to lead to the non-equivalence of terminology translation, and Song Lei divides the vacancies of legal terms into "absolute vacancies" and "relative vacancies". Although the absolute equivalence of terms is difficult to achieve, due to the advancement of legal globalization and the trend of integration between civil law and common law systems, the relative equivalence of terms within the same system can be achieved. In terms of understanding of various fields of law, accurate selection of legal terms and customary expressions, translations aided by parallel corpora are of higher quality than those using traditional resources (Jiang Ting, 2005). Also translators are able to complete translations more quickly and improve translation efficiency. Once the legal bilingual corpus is built, it can be directly used to develop a two-way translation system between English and Chinese to achieve rapid translation between English and Chinese, which greatly changes the traditional translation mode. As far as legal translation practice is concerned, the legal language parallel corpus provides a working platform and reference tool for translators to improve their linguistic and cultural knowledge. In terms of understanding various areas of law, accurate choice of legal terms and customary expressions, translations aided by parallel corpora are of higher quality than those produced by traditional methods such as purely referring to dictionaries. On the basis of improving the efficiency and accuracy of legal translation, it can also promote the development of legal translation.

Establishing a Paradigm in contract law translation is not only important for contract law per se, but also beneficial for other laws. The term "paradigm" was firstly introduced by American philosopher Thomas Kuhn in 1962 in his book 
The Structure of Scientific Revolution. He believes that a paradigm is a recognized pattern followed by a specific scientific community engaged in a certain type of scientific activity, including a common worldview, basic theories, methods, steps, etc.

Understanding is the basis of translation, and only by accurately grasping the core content of laws and regulations can we use accurate words and phrases in the translation process. Culture differs from nation to nation and from country to country, and has its own unique connotation. Language is the carrier of culture, and Chinese and English belong to different language families. Chinese and English reflect different modes of thinking between China and the West. English emphasizes "form fit" and pays much attention to the logical structure of the text, while Chinese emphasizes "meaning fit" and focuses on the internal logical connection of the meaning of the language and is relatively lax in its formal requirements. This difference in the way of thinking and language expression is one of the important influencing factors of legal translation. Therefore, the difference of legal culture is the first factor that translators should consider when translating. Only after understanding the legal culture of the source language country and the target language country, can the translation be carried out in different legal cultural environments, and only then can high-quality legal translation be guaranteed.

The historical process of translation development, contains several branches, such as literary translation, scientific translation, and legal translation and so on. The study of the history of legal translation is an important part of translation research. The study of the history of legal translation contains many aspects, such as dictionaries, translators, translation activities (e.g. contract law), etc. Legal translation since modern times has played a role in promoting the modernization of Chinese law and reshaping Chinese law (Qu Wensheng, 2018). Without the translation of foreign laws, there would be no legal terminology and legal system in modern China. From the perspective of the history of legal terminology translation, given that legal translation follows the principle of precedent and terminology unification $(\mathrm{Qu}$ Wensheng, 2012), the study of the historical process of legal terminology translation provides an important historical basis for translation unification, which is of high reference value for guiding translation practice. The process of creation, development and gradual fixation of semantics of legal terms is one of the key points in the history of legal system, while the formation and definition of transliteration of legal terms is a very important topic in the study of the history of legal translation, and the formation and change of terminology translation has a non-negligible influence on legal practice. After the founding of New China, China had introduced a number of Soviet laws and jurisprudence works, and the translation of these had played a great role in promoting the improvement of China's laws. After the reform and open-up, legal translation re-entered an active period, and China once again translated a large number of laws from the United Kingdom, the United States and other Western countries. Nowadays, legal translation is more active than in any previous era, and is playing the role of bridging the Chinese and Western legal systems and serving the construction of the rule of law. Unlike previous legal translations, the current legal translations in China not only translate into foreign laws, but also pay more attention to translating our laws into foreign languages in order to promote China's foreign rule of law exchanges. The study of the history of legal translation is conducive to a comprehensive understanding of the development of legal translation, so as to learn from it and better complete the translation task.

\section{CONCLUSION}

It is widely acknowledged that as globalization proceeds, the world is becoming more and more closely connected, not only in economic aspects, but also in legal aspects, including contract law. Therefore, in order to be better connected with the international, our laws are bound to learn from the legal systems and rules of other countries in terms of content or form through translation in order to adapt to the trend and tendency of globalization. One of the most crucial factors in learning from and studying the laws of other countries is legal translation, and the quality of legal translation is directly related to the process of China's legal development. In the process of continuous improvement of China's legal system in the future, the role of legal translation will be more important, it is like a catalyst to accelerate the communication between countries in the legal field and play an indispensable role in the process of legal transplantation. However, the study of legal translation has always been a weak link in the development of legal translation, and at present, China's legal translation has not yet built a normative legal translation system, no authoritative methodology as a guide, and no unified English to Chinese standard for legal translation. All the above aspects need to be improved continuously, and the translation industry and the legal academy should work together to establish and improve the discipline of legal translation, so that legal translation can develop in a more scientific direction, and then legal translation can provide better help for the development of China's legal system.

\section{REFERENCES}

[1] Baker, Mona. (2006). Translation and Conflict. London: Routledge.

[2] Eugene, Nida. (1964). Toward a Science of Translating: With Special Reference to Principles and Procedures Involved in Bible Translating. Boston: Brill Academic Publishers.

[3] Daria Martemianova. (2019). Language Difficulties in Legal Translation. Shanghai Jiaotong University, 104-108

[4] Snell-Hornby. (1988). Translation Studies: An Integrated Approach. Amsterdam and Philadelphia: John Benjamins.

[5] Thomas Kuhn. (1962). The Structure of Scientific Revolution. Chicago: University of Chicago Press.

[6] Guo Fang. (2016). Theoretical Development of "faithfulness, expressiveness and elegance" Doctrines. Theories and Practice in 
Education, 36(04), 57-60.

[7] Han Shiyuan. (2015). China's Contract Law Development in Principles of International Commercial Contracts. Globe Law Review(6), 69-82.

[8] Hu Zhaoqing. (2007). Legal Translation and Its Impacts on the Changes of Late Qing Dynasty. East China University of Political Science and Law, 115-150.

[9] Jiang Ting. (2005). The Building of Parallel Corpus in Legal Texts. Journal of Chongqing University, (04), 94-97.

[10] Li Changshuan. (2019). Using Scientific Method to Guide Translation of Terminology. East Journal of Translation, (1), $72-81$.

[11] Li Changshuan. (2017). Critical Thinking throughout the Translation Process. Shanghai Journal of Translators, (5), 32-36.

[12] Li Changshuan. (2006). To Ensure the Accuracy and Natural Sense in Light of Qualification and Quantitation: Application of Electronic Devices in Translation. Chinese Science \& Technology Translators Journal, (3), 22-25.

[13] Liu Chengwei. (2020). The Inspiration from Contract Law Spirits in Common Law System and Influences on the Contract Law Part in China's Civil Code. Social Sciences in Guangdong, (3), 217-226.

[14] Li Jie. (2013). Techniques of English Translation of Contract Law in China. East China University of Political Science and Law, 2013, 2-7.

[15] Li Kexing. (2020). Basic Rules and Procedures for Long Sentences in Legal Texts: Bases on Contract Clauses from English to Chinese. Chinese Translators Journal, (4), 151-161.

[16] Li Kexing. (2018). Translating Legal Texts from Chinese to English: An Empirical Study of an Interpretation Issued by the Supreme People's Court and Supreme People's Procuratorate. Chinese Translators Journal, (5), 94-101.

[17] Li Kexing. (2010). Equivalence in Legal Translation. Foreign Language Teaching and Research, (1), 59-65.

[18] Qu Lin. (2015). The Past and Future of China's Legal Translation. Heilongjiang University, 2015, 4-8.

[19] Qu Wensheng. (2018). The Issues and Methods of Historical Theory Study. Foreign Language Teaching and Research, (6), 832-835.

[20] Qu Wensheng. (2012). The Issues and Reasons for Legal Terminology Translation in China: Regulation Legal Terminology Translation. Chinese Translators Journal, 33(6),68-70.

[21] Wang Liming. (2013). The United Nations Convention on Contracts for the International Sale of Goods, and the Promulgation and Improvement of Contract Law in China. Global Law Review, 35(5), 119-131.

[22] Yu Danling. (2009). CONSIDERATION in Common Law System and Issues on Legal Translation of Terminology. Chinese Translators Journal, (3), 83-86.

[23] Yu Lu. (2015). Study on Thoughts of Chen Zhongcheng on Legal Translation. Shanghai Journal of Translators, (4), 66-69.

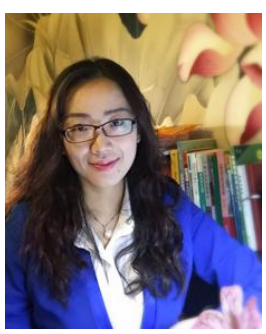

Lin Sun was born in Sichuan, China in 1983. She graduated with First-Class Degree in Xi'an Shiyou University majored in English in 2006, and obtained master degree in Southwest University of Political Science and Law in Forensic Linguistics in 2012, currently she is teaching while conducting doctoral research in Economic Law in Southwest University of Political Science and Law. The domain for her research is legal translation, language teaching and antitrust law.

PUBLICATIONS:

- Regulating the Drivers of On-line Car-Hailing in the Context of Sharing Economy, Venture Capital of China [J] (ISSN 1673-5811), 2016. Vol. 12;

- Local Governments' Use of Covenants to Regulate Land Use, Research on Real Estate Law of China [J] (CSSCI, IF 1.67), 2017.Vol.15;

- Workplace Writings: Focus on Doing [M] (English version, editor for "Contract writing" part), China Renmin University Press, 2016

- Big Law [M] (trans., English to Chinese), Law Press of China, 2017;

- How to Argue and Win Every Time [M] (trans., English to Chinese), Law Press of China, 2017;

- Client Management for Lawyers [M] (trans., English to Chinese), Law Press of China, 2018;

- The Exclusionary Rule of Illegal Evidence in China [M] (trans., Chinese to English, Funded by Chinese Fund for the Humanity and Social Science), Springer, 2019;

- The Basic Issues Regarding Criminology Theory [M] (trans., Chinese to English, Funded by Chinese Fund for the Humanity and Social Science), Springer (forthcoming);

- The History of the Contractual Thoughts in Ancient China [M] (trans., Chinese to English, Funded by Chinese Fund for the Humanity and Social Science), Springer;

- Basic Contract Law [M] (trans., English to Chinese), China Legal Publishing House (forthcoming);

- Invited Speaker-“Court Interpretation of Criminal Cases: Empirical Studies in Chongqing”, Martin Centre's 3rd International Conference Appliable Linguistics and Legal Discourse, Shanghai Jiao Tong University 14th - 18th December 2016.

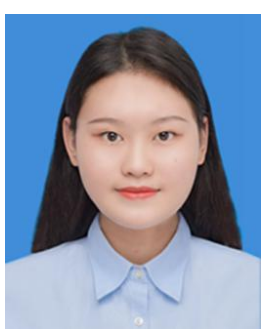

Dexiang Gong was born in Chongqing, China in 1997. She received her bachelor's degree in arts from Southwest University of Political Science \& Law, China in 2021.She is currently pursuing her Master's degree in Law in Southwest University of Political Science \& Law, China. 